\title{
Special issue in honor of Berç Rustem
}

\author{
Hans Amman • Panos Pardalos
}

Received: 3 May 2014 / Accepted: 23 May 2014 / Published online: 24 June 2014

(C) Springer-Verlag Berlin Heidelberg 2014

\section{Introduction to this special issue}

Last year Berç Rustem stepped down as the founding editor of this journal, Computational Management Science. Over the years the journal benefited greatly from Berç's editorship. The journal has established itself and has become a leading journal in the field.

Through his work, Berç Rustem has influenced a number of scientific areas ranging from Economics, Operations Research to Robust control. This is reflected in his early work in Economics, Projection Methods in Constrained Optimisation and Applications to Optimal Policy Decisions (1981) and later on in his works Algorithms for Nonlinear Programming and Multiple Objective Decisions (1998) and Algorithms for Worst-case Design with Applications to Risk Management (2002). The latter being a standard work of robust control in Economics.

As friends, we are happy to see that over the years Berç remained very productive as an academic and we are sure he will continue this path for many years to come. This special issue is a collection of papers in these areas by his friends and colleagues, to celebrate his leadership for the journal and our scientific community.

\section{References}

Rustem B (1981) Projection methods in constrained optimisation and applications to optimal policy decisions., Lecture Notes in Control and Information SciencesSpringer, New York

H. Amman $(\varangle) \cdot$ P. Pardalos

Department of Mathematical Economics and Mathematics, University of Amsterdam, Spui 21,

Amsterdam1012 WX, The Netherlands

e-mail: hans.amman@gmail.com

P. Pardalos

Center for Applied Optimization, ISE Department, University of Florida,

Gainesville, FL 32611, USA 
Rustem B (1998) Algorithms for nonlinear programming and multiple objective decisions. John Wiley, New York

Rustem B, Howe MA (2002) Algorithms for worst-case design with applications to risk management. Princeton University Press, Princeton 